\title{
PARTISIPASI PEMUDA DALAM PENGELOLAAN HUTAN KEMASYARAKATAN DI DESA KAHAYYA KABUPATEN BULUKUMBA
}

\author{
Youth participation Youth Participation In Community Forest Management in \\ Kahayya Village Bulukumba District
}

\author{
Andi Atira IIfa ${ }^{1}$, Supratman ${ }^{2}$, Muhammad Alif K.S. ${ }^{2}$ \\ ${ }^{1}$ Program Studi Perencanaan dan Pengembangan Wilayah Sekolah Pascasarjana \\ Universitas Hasanuddin, Makassar \\ ${ }^{2}$ Jurusan IImu Kehutanan, Fakultas Kehutanan Universitas Hasanuddin, Makassar
}

“Email : andiatirailfa@gmail.com

Diterima : 07/08/2020, Direvisi :16/09/2020, Diterbitkan 01/03/2021

\begin{abstract}
This study aims to analyze the level of youth participation in community forest (HKm) management, analyze the driving forces and restraining forces of youth participation in community forest management and formulate strategies for increasing youth participation in community forest management. The data obtained were identified and reviewed in the form of a frequency table of Arnstein's degree of involvement, then analyzed descriptively by the Forces Field Analysis and Focus Group Discussion methods. The results showed the level of youth participation was at the degree of non-participation, with a percentage of $71.43 \%$. The factors that encourage youth participation consist of the group facilitator, group meetings, work plan documents, assistance from various parties, the formation of the Social Forestry Business Group (KUPS), and the desire of youth to participate. The factors that inhibit youth participation consist of: lack of youth knowledge in managing community forest, not yet implementing work boundary arrangement activities, youth are not involved in the process of making work plans, and community forest implementation is still carried out individually, the farming experience is still lacking, lack of group capital makes the price of raw materials unstable. An appropriate strategy for increasing youth participation in the management of community forest consists of Conducting meetings involving facilitator, farmer groups and youth to discuss the implementation of management activities (planning, implementation \& evaluation) of the community forest-conduct socialization and meetings regarding the contents of the community forest documents that have been made. Make internal group rules regarding product sales prices. Enhance the role of KUPS and conduct training for KUPS administrators to increase their capacity. Youth participate in various types of training conducted by government and non-government organizations (NGOs).
\end{abstract}

Keywords; Youth Participation, Community Forest

\begin{abstract}
ABSTRAK
Penelitian ini bertujuan untuk menganalisis tingkat pertisipasi pemuda dalam pengelolaan $\mathrm{HKm}$, menganalisis faktor pendorong dan faktor penghambat partisipasi pemuda dalam pengelolaan $\mathrm{HKm}$ dan merumuskan strategi peningkatan partisipasi pemuda dalam pengelolaan $\mathrm{HKm}$. Data yang diperoleh diidentifikasi dan dikaji dalam bentuk tabel frekuensi derajat partisipasi Arnstein, kemudian dianalisis secara deskriptif dengan metode Forces Field Analysis dan Focus Group Discussion. Hasil penelitian
\end{abstract}


menunjukkan tingkat partisipasi pemuda berada pada derajat partisipasi non-participation dengan persentase $71,43 \%$. Faktor pendorong partisipasi pemuda terdiri atas: adanya pendamping kelompok, pertemuan kelompok, dokumen rencana kerja, bantuan dari berbagai pihak, terbentuknya Kelompok Usaha Perhutanan Sosial (KUPS), dan keinginan pemuda untuk berpartisipasi. Faktor penghambat partisipasi pemuda terdiri atas: kurangnya pengetahuan pemuda dalam pengelolaan $\mathrm{HKm}$, belum terlaksananya kegiatan penataan batas arel kerja, pemuda tidak dilibatkan dalam proses pembuatan rencana kerja, pelaksanaan $\mathrm{HKm}$ masih dilakukan sendiri-sendiri, pengalaman bertani masih kurang, modal kelompok tidak ada mengakibatkan harga jual bahan baku tidak stabil. Strategi yang sesuai dalam peningkatan partisipasi pemuda dalam pengelolaan $\mathrm{HKm}$ terdiri atas: Melakukan pertemuan yang melibatkan pendamping, kelompok tani dan pemuda untuk membahas pelaksanaan kegiatan pengelolaan (perencanaan, pelaksanaan \& evaluasi) $\mathrm{HKm}$. melakukan sosialisasi dan rapat mengenai isi dokumen rencana kerja $\mathrm{HKm}$ yang telah dibuat. Membuat aturan internal kelompok mengenai harga penjualan produk. Meningkatkan peran KUPS dan melakukan pelatihan bagi pengurus KUPS untuk meningkatkan kapasitasnya. Pemuda ikut serta dalam berbagai jenis pelatihan yang dilakukan oleh pemerintah maupun lembaga non pemerintah (LSM).

Kata kunci; Partisipasi, pemuda, Hutan Kemasyarakatan.

\section{PENDAHULUAN}

Perhutanan sosial telah diamanatkan dalam Undang-undang Nomor 41 Tahun 1999 tentang Kehutanan. Undang-undang Nomor 41 Tahun 1999 Pasal 3 huruf d menyebutkan bahwa penyelenggaraan kehutanan bertujuan untuk sebesar-besar kemakmuran rakyat yang berkeadilan dan berkelanjutan dengan meningkatkan kemampuan dalam mengembangkan kapasitas dan keberdayaan masyarakat secara partisipatif, berkeadilan dan berwawasan lingkungan. Salah satu skema perhutanan sosial yang ada saat ini adalah Hutan Kemasyarakatan (HKm) (PermenLHK No. 83 Tahun 2016).

Hutan Kemasyarakatan $(\mathrm{HKm})$ merupakan skema perhutanan sosial dalam hutan negara yang bertujuan agar masyarakat dapat diberdayakan dalam pengelolaan hutan, yang dikelola secara lestari dan dapat meningkatkan kesejahteraannya (Kaskoyo et al, 2014). Melalui HKm diharapkan dapat mengembangkan kapasitas masyarakat serta pemberian akses kepada masyarakat setempat guna menjamin ketersediaan lapangan kerja untuk memecahkan persoalan ekonomi dan sosial (Nandini, 2013). Hutan kemasyarakatan juga berkontribusi terhadap penghasilan anggota kelompok tani hutan (KTH) $6.4 \%$ dari total pendapatannya (Dewi et al, 2018). Angka tersebut bisa lebih tinggi jika pengelolaan $\mathrm{HKm}$ dapat dioptimalkan.

Keberhasilan pembangunan HKm sangat ditentukan oleh ketersediaan dan kualitas sumber daya manusia. Dalam pembangunan $\mathrm{HKm}$, pihak pengelola diharuskan memiliki kemampuan dalam mengelola lembaga sehingga setiap kegiatan dalam pengelolaan $\mathrm{HKm}$ dapat berjalan sesuai dengan yang diharapkan. Salah satu sumber daya manusia yang potensial diberdayakan dalam pembangunan $\mathrm{HKm}$ adalah pemuda.

Pengelolaan hutan secara lestari tentunya tidak boleh dilepaskan dari partisipasi pemuda. Partisipasi pemuda dalam pengelolaan hutan masih tergolong sebagai partisipasi yang sangat tidak aktif (Sinery \& Manusawai, 2016). Hasil penelitian yang dilakukan Winata dan Yuliana (2012) terhadap partisipasi petani hutan dalam pengelolaan hutan, golongan umur pemuda usia 18-35 tahun masih sangat minim yaitu 4\%. Nilai tersebut menunjukkan kurangnya partisipasi pemuda dalam pengelolaan hutan, hal tersebut tentunya tidak sejalan dengan tujuan pembentukan perhutanan sosial dalam hal penyerapan tenaga kerja, mengurangi kemiskinan, meningkatkan pertumbuhan dan 
memperbaiki kualitas lingkungan. Pemuda sebagai generasi penerus dan memiliki kapasitas untuk menyerap informasi dan teknologi lebih baik, harusnya terlibat aktif dalam proses pengelolaan hutan.

Upaya untuk melibatkan pemuda dalam pembangunan $\mathrm{HKm}$ harus terus dilakukan. Minimnya informasi terkait tingkat partisipasi serta faktor pendorong dan penghambat partisipasi pemuda menjadi kendala dalam upaya pelibatan tersebut. Penelitian terkait partisipasi pemuda dalam pembangunan $\mathrm{HKm}$ masih jarang dilakukan. Kondisi tersebut menjadi acuan dalam melakukan penelitian ini. Penelitian ini bertujuan untuk menganalisis tingkat partisipasi pemuda dalam pembangunan $\mathrm{HKm}$ di Desa Kahayya Kecamatan Kindang Kabupaten Bulukumba. Selain itu, penelitian ini juga menganalisis faktor pendorong dan penghambat partisipasi pemuda dalam merumuskan strategi peningkatan partisipasi pemuda terhadap pengelolaan Perhutanan Sosial di Hutan Kemasyarakatan Desa Kahayya Kecamatan Kindang Kabupaten Bulukumba.

\section{METODE}

\section{A. Lokasi Penelitian}

Penelitian ini dilaksanakan di areal Hutan Kemasyarakatan ( $\mathrm{HKm})$ di Desa Kahayya Kecamatan Kindang, Kabupaten Bulukumba pada bulan Januari hingga Agustus 2020. Peta lokasi penelitian dapat dilihat pada Gambar 1.

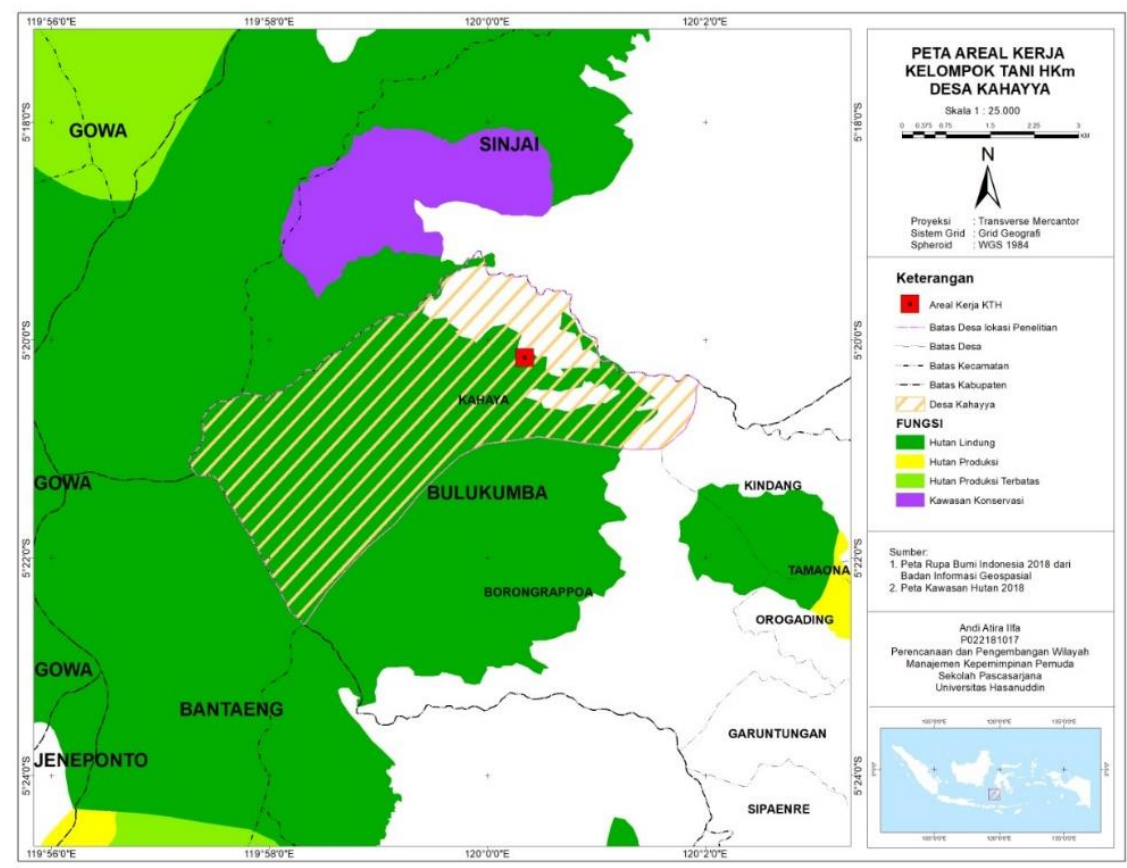

Gambar 1 Peta Lokasi Penelitian

Figure 1. Map of research location

\section{B. Pengumpulan Data.}

Pengumpulan data dilakukan dengan metode wawancara menggunakan pedoman wawancara, studi dokumen dari instansi terkait dan Focus Group Discussion (FGD). Wawancara dilakukan untuk mengetahui tingkat partisipasi pemuda dalam pengelolaan $\mathrm{Hkm}$ pada proses pembangunan yaitu pada tahap perencanaan dengan kriteria penataan areal kerja dan pembuatan rencana kerja, pelaksanaan $\mathrm{HKm}$ dinilai pada kriteria pemeliharaan, penanaman, pengamanan, pemanenan dan pemasaran, tahap evaluasi dinilai pada kriteria pembuatan dan penyampaian laporan. 
Dalam pedoman wawancara terdapat 8 pertanyaan pada masing-masing kriteria dengan pilihan jawaban "ya" dan "tidak". Jawaban "tidak" diberi nilai 0 dan jawaban "ya" diberi nilai 1. Pertanyaan bersifat tingkatan sehingga untuk menilai tingkat partisipasi pemuda dilihat sampai responden memilih jawaban "tidak", apabila responden memilih jawaban "tidak" berarti tidak dapat melanjutkan ke pertanyaan berikutnya. Pengambilan data dilakukan terhadap 21 orang pemuda berumur 16-30 tahun yang mengelola $\mathrm{HKm}, 9$ orang terdaftar sebagai anggota KTH dan 11 adalah anak dari anggota kelompok KTH.

\section{Analisis Data}

Analisis yang digunakan dalam penelitian ini meliputi analisis tingkat partisipasi menggunakan tangga partisipasi Arnstein. Tingkat partisipasi pemuda dalam 8 kriteria (kegiatan) dikategorikan menjadi tiga kategori derajat partisipasi dari delapan tangga partisipasi, dilihat berdasarkan skor berikut: Non-participation: 0-2, Tokenism: 3-5 dan Citizien Control: 6-8. Pada setiap kriteria dengan skor total 64, dikategorikan menjadi Nonparticipation: 0-16, Tokenism: 17-24 dan Citizen control: 25-64.

Setelah diperoleh data mengenai tingkat/derajat partisipasi pemuda dalam pengelolaan $\mathrm{HKm}$, selanjutnya dilakukan analisis mengenai faktor-faktor pendorong dan penghambat partisipasi pemuda menggunakan metode Force Field Analisys (FFA) yang dikembangkan oleh Kurt Lewin (1951). Force Field Analisys digunakan untuk pengambilan keputusan dengan menganalisi kekuatan untuk melawan perubahan dan untuk mengkomunikasikan alasan dibalik keputusan atau tujuan. Dalam FGD yang dilakukan dengan anggota $\mathrm{KTH}$, disusun strategi atau cara (ways) untuk memperkuat faktor pendorong (driving forces) dan memperlemah atau memberikan alternatif untuk mengurangi faktor penghambat (restraining forces). Setelah strategi atau cara (ways) tersebut diperoleh, selanjutnya dirumuskan rencana aksi (clear action) yang dapat dilakukan secara nyata untuk meningkatkan partisipasi pemuda dalam pengelolaan Hutan Kemasyarakatan di Desa Kahayya Kecamatan Kindang Kabupaten Bulukumba.

\section{HASIL DAN PEMBAHASAN,}

\section{A. Analisis Tingkat Partisipasi Pemuda dalam Pengelolaan HKm}

Tingkat partisipasi pemuda dalam pengelolaan HKm secara keseluruhan dapat dilihat pada Tabel 1. Partisipasi pemuda dalam Pembangunan Hutan Kemasyarakatan $(\mathrm{HKm})$ di Desa Kahayya paling besar berada pada derajat Non-Partisipation dengan persentase $71,43 \%$.

Tabel 1. Tingkat Partisipasi Pemuda dalam Pengelolaan HKm

Table 1. The level of youth participation in the implementation of community forest.

\begin{tabular}{ccc}
\hline Tingkat partisipasi & Jumlah & Persentase \\
\hline Non-participation & 15 & $71.43 \%$ \\
Tokenism & 6 & $28.57 \%$ \\
Citizien Control & 0 & $0.00 \%$ \\
Total & 21 & $100.00 \%$ \\
\hline
\end{tabular}

Sumber: Analisis Data Primer, 2020

Kategori Non-Participation dalam derajat partisipasi menurut Arnstein (1969) termasuk ke dalam tingkat bukan partisipasi yang sesungguhnya, dimana tujuannya bukan untuk memungkinkan masyarakat berpartisipasi, tetapi hanya untuk "mendidik" atau 
"menyembuhkan" anggota komunitas. Hal ini menunjukkan bahwa tingkat partisipasi pemuda dalam pengelolaan $\mathrm{HKm}$ masih sangat rendah.

\section{A.1. Tingkat partisipasi pemuda pada perencanaan $\mathrm{HKm}$}

Hasil dari penilaian partisipasi pemuda dalam Pembangunan Hutan Kemasyarakatan $(\mathrm{HKm})$ pada tahap perencanaan, disajikan dalam Tabel 2.

Tabel 2. Tingkat partisipasi pemuda dalam tahap perencanaan $\mathrm{HKm}$

Table 2. The level of youth participation in planning of community forest.

\begin{tabular}{ccc}
\hline Tingkat partisipasi & Jumlah & Persentase \\
\hline Non-participation & 21 & $100.00 \%$ \\
Tokenism & 0 & $0.00 \%$ \\
Citizien Control & 0 & $0.00 \%$ \\
Total & 21 & $100.00 \%$ \\
\hline
\end{tabular}

Sumber: Analisis Data Primer, 2020

Hasil penelitian ini menunjukkan bahwa pada tahap perencanaan dalam kegiatan penataan batas areal kerja, tingkat partisipasi pemuda masih berada pada tingkatan NonParticipation, sebesar $100 \%$. Seluruh responden berada pada tangga manipulasi dan terapi yang menunjukkan bahwa minimnya partisipasi pemuda dalam proses penataan batas areal kerja dan penyusunan rencana kerja $\mathrm{HKm}$.

Penyusunan rencana kerja HKm dilakukan sebagai acuan bagi pemegang izin IUPHKm dalam melaksanakan kegiatan pengelolaan hutan dan sebagai pengendalian bagi pemerintah. Berdasarkan hasil studi dokumen yang peneliti dapatkan, Rencana kerja usaha IUPHKm KTH periode 2019 sampai 2028 telah terbit, yang difasilitasi oleh Pendamping $\mathrm{HKm}$ dalam hal ini penyuluh PNS, yang disahkan oleh Kepala UPT KPH Jeneberang II pada bulan agustus 2019. Penyusunan rencana kerja difasilitasi oleh pendamping dan Ketua Kelompok. Pemuda sebagai anggota kemudian tidak dilibatkan, hal ini tentunya belum sejalan dengan konsep perhutanan sosial yang dibentuk dengan melibatkan peran serta berbagai unsur sosial. Perhutanan sosial menuntut pelibatan peran serta berbagai pihak (berbagai unsur sosial) yang dapat dilakukan dimana saja, di lahan milik pribadi, umum atau di kawasan hutan yang diijinkan (Arifandy dan Sihaloho, 2015).

\section{A.2. Tingkat partisipasi pemuda pada pelaksanaan $\mathrm{HKm}$}

Tingkat/derajat partisipasi pemuda dalam pelaksanaan $\mathrm{HKm}$ dapat dilihat pada Tabel 3. Tingkat partisipasi pemuda pada proses pelaksanaan $\mathrm{HKm}$ berada dalam tingkat/derajat Tokenism dengan nilai 90,48\%. Hal tersebut menunjukkan bahwa partipasi pemuda dalam tahap pelaksanaan merupakan partisipasi semu, dimana pemuda mendapatkan informasi tentang proses pelaksanaan $\mathrm{HKm}$ dan pemuda dapat memberikan saran, pendapat atau ide, tetapi saran, pendapat atau ide yang diberikan tersebut belum tentu mempengaruhi jalannya tahap pelaksanaan program $\mathrm{HKm}$.

Tabel 3. Tingkat partisipasi pemuda dalam pelaksanaan $\mathrm{HKm}$

Table 3. The level of youth participation in the implementation of community forest

\begin{tabular}{ccc}
\hline Tingkat partisipasi & Jumlah & Persentase \\
\hline Non-participation & 2 & $9.52 \%$ \\
Tokenism & 19 & $90.48 \%$ \\
Citizien Control & 0 & $0.00 \%$ \\
Total & 21 & $100.00 \%$ \\
\hline
\end{tabular}

Sumber: Analisis Data Primer, 2020 
Pada tahap pelaksanaan merupakan salah satu aktivitas yang paling banyak mengedepankan komunikasi partisipatif yang melibatkan seluruh anggota. Hal ini sejalan dengan hasil temuan Satriani et al. (2015) di mana komunikasi partisipatif dalam suatu lembaga selain menjadi ajang berbagi informasi dan pengetahuan, juga menjadi wadah untuk penyelesaian permasalahan secara bersama-sama sehingga diharapkan akan terjalin keakraban yang lebih erat antar sesama anggota.

\section{A.3. Tingkat partisipasi pemuda pada evaluasi $\mathrm{HKm}$}

Tahap evaluasi Hkm melalui pembuatan dan penyampaian laporan dilakukan untuk mengetahui perkembangan program dalam hal ini pengelolaan $\mathrm{HKm}$. Partisipasi pemuda pada tahap pembuatan dan penyampaian laporan berda pada tingkat Non-participation dengan persentase $100 \%$ (Tabel 4).

Tabel 4. Tingkat partisipasi pemuda dalam pengelolaan $\mathrm{HKm}$ pada kegiatan Evaluasi.

Table 4. Level of youth participation in evaluation activities of Community Forest.

\begin{tabular}{ccc}
\hline Tingkat partisipasi & Jumlah & Persentase \\
\hline Non-participation & 21 & $100.00 \%$ \\
Tokenism & 0 & $0.00 \%$ \\
Citizien Control & 0 & $0.00 \%$ \\
Total & 21 & $100.00 \%$ \\
\hline
\end{tabular}

Sumber: Analisis Data Primer, 2020

Tingkat partisipasi Pemuda dalam proses evaluasi berada dalam tingkat/derajat Non-participation dimana dalam tingkatan ini, pemuda hanya terlibat sebagai formalitas semata, namun berdasarkan hasil penelitian yang dilakukan di lapangan, pelaksanaan evaluasi pembuatan dan penyampaian laporan belum berjalan, disebabkan dokumen perencanaan terbit tahun 2019 dan dalam proses pelaksanaan kelompok masih bekerja sesuai dengan kebiasaan yang dilakukan, Guniastuti et al. (2014) dalam Tanjung et al. (2017) menyebutkan bahwa rendahnya partisipasi anggota masyarakat dalam kegiatan monitoring dan evaluasi disebabkan oleh belum adanya kesesuaian antara perecanaan dan pelaksanaan.

\section{B. Analisis Faktor Pendorong Dan Faktor Penghambat Partisipasi Pemuda Dalam Pengelolaan Hutan Kemasyarakatan (Hkm)}

Hasil analisis faktor pendorong dan penghambat partisipasi pemuda dalam pengelolaan $\mathrm{HKm}$ dapat dilihat pada Tabel 5. Setiap variabel dijadikan isu dalam menganalisis faktor-faktor pendorong dan faktor-faktor penghambat pemuda dalam berpartisipasi.

Tabel 5. Faktor-faktor pendorong (driving force) dan faktor-faktor penghambat (restraining force) partisipasi pemuda dalam pengelolaan $\mathrm{HKm}$.

Table 5. Driving force and restraining force of youth participation in community forest management.

\begin{tabular}{|c|c|c|}
\hline Variabel & Faktor Pendorong & Faktor Penghambat \\
\hline $\begin{array}{l}\text { Perencanaan: } \\
\text { 1. Penataan Batas } \\
\text { Areal Kerja } \\
\text { 2. Penyusunan } \\
\text { Rencana Kerja }\end{array}$ & $\begin{array}{l}\text { 1. Adanya pendamping kelompok } \\
\text { 2. Adanya pertemuan kelompok } \\
\text { 3. Keinginan anggota kelompok } \\
\text { untuk memperjelas areal kerja } \\
\text { HKm } \\
\text { 4. Adanya keinginan pemuda } \\
\text { untuk berpartisipasi dalam }\end{array}$ & $\begin{array}{l}\text { 1. Kurangnya pemahaman pemuda } \\
\text { mengenai proses perencanaan } \\
\text { HKm } \\
\text { 2. Belum terlaksananya penataan } \\
\text { areal kerja. } \\
\text { 3. Pemuda tidak dilibatkan dalam } \\
\text { penyusunan Rencana Kerja }\end{array}$ \\
\hline
\end{tabular}


kegiatan penataan batas areal

kerja dan penyusunan rencana

kerja

Lanjutan Tabel 5. Faktor-faktor pendorong (driving force) dan faktor-faktor penghambat (restraining force) partisipasi pemuda dalam pengelolaan $\mathrm{HKm}$.

Continued Table 5. Driving force and restraining force of youth participation in community forest management.

\begin{tabular}{|c|c|c|}
\hline Variabel & Faktor Pendorong & Faktor Penghambat \\
\hline & $\begin{array}{l}\text { 5. Adanya dokumen Rencana } \\
\text { Kerja Usaha (RKU) dan } \\
\text { Rencana Kerja Tahunan } \\
\text { (RKT) tahun 2019-2028 }\end{array}$ & \\
\hline $\begin{array}{l}\text { Pelaksanaan: } \\
\text { 1. Pemeliharaan } \\
\text { 2. Penanaman } \\
\text { 3. Pengamanan } \\
\text { 4. Pemanenan } \\
\text { 5. Pemasaran }\end{array}$ & $\begin{array}{l}\text { 1. Adanya pendamping } \\
\text { kelompok } \\
\text { 2. Adanya bantuan alat ekonomi } \\
\text { produktif dari BPSKL } \\
\text { 3. Adanya bantuan bibit } \\
\text { 4. Adanya program } \\
\text { pemberdayaan dari LSM } \\
\text { 5. Adanya Kelompok Usaha } \\
\text { Perhutanan Sosial }\end{array}$ & $\begin{array}{l}\text { 1. Proses pelaksanaan HKm masih } \\
\text { dilakukan secara sendiri-sendiri } \\
\text { 2. Kurangnya pemahaman pemuda } \\
\text { dalam proses pelaksanaan HKm } \\
\text { 3. Pengalaman Bertani masih } \\
\text { kurang } \\
\text { 4. Modal kelompok tidak ada } \\
\text { 5. Harga jual bahan baku tidak stabil }\end{array}$ \\
\hline $\begin{array}{l}\text { Evaluasi } \\
\text { Pembuatan dan } \\
\text { Penyampaian Laporan }\end{array}$ & $\begin{array}{l}\text { Adanya keinginan pemuda } \\
\text { dalam proses evaluasi }\end{array}$ & $\begin{array}{l}\text { 1. Kurangnya pengetahuan } \\
\text { pemuda mengenai tahap } \\
\text { evaluasi. } \\
\text { 2. Pembuatan laporan belum } \\
\text { dilaksanakan }\end{array}$ \\
\hline
\end{tabular}

Sumber: Analisis Data Primer, 2020

\section{B.1. Faktor Pendorong partisipasi pemuda dalam pengelolaan HKm.}

\section{B.1.1. Perencanaan.}

Peran pendamping akan meningkatkan pengetahuan masyarakat mengenai program yang dilaksanakan dan diharapkan akan menciptakan kondisi yang baik dalam pelaksanaan program, sehingga masyarakat dan pendamping akan berkolaborasi dalam menyukseskan suatu program. Hal tersebut juga sejalan dengan Hikmah et al. (2018) yang menyatakan karena adanya pendampingan akan meningkatkan kapasitas masyarakat dan menciptakan kerja sama dalam pemberian pengetahuan antara pendamping dan yang didampingi. Hasil temuan yang dilakukan di lapangan, pendamping sekaligus Penyuluh Kehutanan Pegawai Negeri Sipil yang biasa disebut dengan Penyuluh PNS telah berupaya membantu masyarakat khususnya kelompok tani untuk meningkatkan kapasitasnya dalam melaksanakan perencanaan dengan membantu kelompok tani dalam perumusan dokumen Rencana Kerja berupa dokumen Rencana Kerja Usaha (RKU) dan Rencana Kerja Tahunan (RKT) tahun 2019-2028.

Faktor pendorong selanjutnya ialah adanya keinginan kelompok tani khususnya pemuda dalam upaya memperjelas batas areal kerja HKm yang sampai saat ini belum dilaksanakan serta adanya keinginan pemuda untuk terlibat dalam pelaksanaan kegiatan penataan batas areal kerja dan penyusunan rencana kerja $\mathrm{HKm}$, Penyusunan dokumen RKT dan RKU yang telah dilakukan tidak melibatkan pemuda pada saat proses pembuatannya, tetapi yang dilibatkan hanya ketua kelompok tani. Hal tersebut relevan dengan temuan Winata dan Yuliana (2012) bahwa dalam kegiatan pengelolaan seperti perencanaan dan monitoring evaluasi, anggota kurang diikutsertakan oleh pengurus. 


\section{B.1.2. Pelaksanaan}

Faktor yang mendorong pemuda dalam pelaksanaan $\mathrm{HKm}$ antara lain, adanya pendamping kelompok, adanya bantuan alat ekonomi produktif dari Balai Perhutanan Sosial dan Kemitraan Lingkungan (BPSKL), adanya bantuan bibit, adanya program pemberdayaan dari LSM, dan adanya Kelompok Usaha Perhutanan Sosial.

Pendamping sangat berperan penting dalam keberhasilan program $\mathrm{HKm}$, pendamping dan masyarakat harus bekerjasama dalam menjalankan fungsinya masingmasing untuk mencapai tujuan pembangunan $\mathrm{HKm}$ untuk meningkatkan kesejahteraan masyarakat sekitar hutan dengan pemanfaatan sumber daya hutan yang optimal, adil dan berkelanjutan, dengan senantiasa menjaga kelestariannya. Faktor pendorong dengan adanya bantuan alat ekonomi produktif dari BPSKL Wilayah Sulawesi berupa mesin sangrai dan penghalus kopi merupakan salah satu upaya mensejahterakan kelompok tani dan masyarakat setempat dan adanya bantuan bibit yang telah diterima oleh kelompok tani dan telah dimanfaatkan. Sejalan dengan Mulyadin et al. (2016) menyatakan bahwa dengan keikutsertaan dalam program $\mathrm{HKm}$ masyarakat akan memperoleh manfaat yaitu mendapat akses legal ke dalam hutan negara, mendapat bantuan teknis, dan subsidi penyiapan bibit tanaman.

Faktor pendorong dengan adanya program pemberdayaan dari Lembaga Swadaya Masyarakat (LSM), dalam hal ini Sulawesi Community Foundation (SCF) pada salah satu programnya telah memberikan beberapa pelatihan terhadap kelompok tani dan masyarakat setempat, salah satunya dengan pelatihan ekonomi kreatif, yang menghasilkan produk kopi kahayya. Sejalan dengan penelitian yang dilakukan oleh Ruhimat (2013) aspek dukungan LSM merupakan aspek yang berpotensi meningkatkan pertisipasi masyarakat dalam implementasi kebijakan, dukungan LSM tersebut dalam bentuk pembinaan dan pendampingan masyarakat dalam setiap proses implementasi kebijakan. Setelah dukungan pemerintah dan tokoh masyarakat, dukungan LSM juga memiliki peranan penting dalam meningkatkan partisipasi masyarakat.

Kelompok Usaha Perhutanan Sosial (KUPS) yang terbentuk di Desa Kahayya berdasarkan kesamaan usaha dan komoditi yang dilaksanakan oleh anggotanya, merupakan faktor pendorong dalam pelaksanaan HKm. Terbentuknya KUPS di Desa Kahayya merupakan salah satu upaya peningkatan kelembagaan usaha dan/atau kewirausahaan dalam melakukan kegiatan pengembangan usaha dibidang Perhutanan Sosial, dalam hal pemasaran KUPS diharapkan mampu memfasilitasi anggotanya untuk pemasaran produk, namun KUPS yang terbentuk tergolong masih baru dan masih belum melaksanakan usahanya secara bersama-sama.

\section{B.1.3. Evaluasi}

Faktor pendorong partisipasi pemuda dalam tahap evaluasi program HKm dinilai dari pembuatan dan penyampaian laporan, adanya keinginan pemuda untuk berpartisipasi dalam proses pembuatan laporan, sejalan dengan Mulyadin et al. (2016) salah satu aspek penting dalam pelaksanaan program $\mathrm{HKm}$ adalah keinginan untuk ikut serta dalam kegiatan pengelolaan hutan harus datang dari masyarakat tanpa unsur paksaan. Hal tersebut merupakan peluang yang dapat dipertimbangkan ketua kelompok dan pendamping untuk memberdayakan pemuda agar ikut berpartisipasi ketika akan membuat laporan kinerja yang telah dicapai sesuai dengan Rencana Kerja yang telah dibuat dan dilaksanakan. Hal tersebut didukung oleh Undang-undang Nomor 40 Tentang Kepemudaan pasal 1 ayat 6 yang menyatakan pemberdayaan pemuda adalah kegiatan membangkitkan potensi dan peran aktif pemuda. 


\section{B.2. Faktor Penghambat partisipasi pemuda dalam pengelolaan HKm.}

\section{B.2.1. Perencanaan}

Faktor penghambat partisipasi pemuda dalam proses perencanaan terlihat dari kurangnya pemahaman pemuda mengenai proses perencanaan $\mathrm{HKm}$, mengakibatkan pemuda hanya melakukan kegiatan pengolahan sesuai dengan kebiasaan turun temurun yang telah diajarkan oleh orang tua mereka, serta karena belum terlaksananya penataan areal kerja mengakibatkan pemuda hanya melakukan kegiatan pelaksanaan di lahan yang telah digarap dari dulu. Selain itu, Pemuda tidak dilibatkan dalam penyusunan Rencana Kerja, pembuatan rencana kerja disusun oleh ketua kelompok tani yang difasilitasi oleh penyuluh/pendamping $\mathrm{HKm}$. Pembuatan rencana kerja sebaiknya dilakukan secara bersama-sama dengan pertimbangan setiap anggota berhak memberikan pendapat dalam rencana kerja yang akan dilaksanakan nantinya, sesuai dengan peraturan Undang-undang nomor 40 pasal 8 ayat 1 (d) tentang kepemudaan dalam strategi pelayanan kepemudaan dengan pemberian kesempatan yang sama untuk berekspresi, beraktivitas dan berorganisasi sesuai dengan ketentuan peraturan perundang-undangan.

\section{B.2.2. Pelaksanaan}

Dalam Proses pelaksanaan HKm faktor penghambat yang telah dikaji yaitu pelaksanaan $\mathrm{HKm}$ masih dilakukan secara sendiri-sendiri, hal ini menunjukkan peran kelompok tani sebagai wahana belajar, bekerjasama dan wahana produksi belum berjalan maksimal. Pada proses pemasaran produk atau hasil usaha taninya juga demikian, kondisi ini yang mengakibatkan ketidak stabilan harga. Ramdhani et al. (2015) berpendapat, sebagai suatu organisasi sosial kelompok tani adalah suatu wadah untuk belajar maupun mengajar bagi setiap anggotanya guna mendapatkan pengetahuan, keterampilan, dan sikap serta bertumbuh dan berkembanganya suatu kemandirian didalam berusahatani dengan suatu produktivitas yang meningkat, pendapatan yang bertambah dan kehidupan yang sejahtera.

Kelompok tani belum mampu berperan dalam meningkatkan daya tawar dalam penentuan harga suatu komoditi, hal ini disebabkan juga karena modal kelompok tani dalam menyerap produk kurang, maka anggota kelompok pada umumnya memasarkan hasil produknya langsung ke pedagang/pengepul. Hal tersebut sejalan dengan temuan Reski et al. (2017) yang mengatakan akses masyarakat terhadap modal, pasar, iptek dan dalam proses pengambilan kebijakan sangat minim sehingga masyarakat masih dalam kondisi marginal, apatis dan susah untuk mengembangkan unit usaha. Kurangnya pemahaman pemuda dalam proses pelaksanaan $\mathrm{HKm}$ juga menjadi faktor penghambat dalam berpartisipasi, pemuda hanya melakukan kegiatan pelaksanaan sesuai dengan apa yang dilakukan oleh orangtuanya, dan pada rentang usia yang masih tergolong muda pengalaman dalam bertani masih kurang. Sejalan dengan penelitian yang dilakukan oleh Tanjung et al. (2017), terhadap anggota kelompok berusia 30-49 tahun menemukan bahwa kemampuan anggota berusia produktif lebih mampu menerima informasi dan mengadopsi teknologi agar pengelolaan hutan berlangsung lebih optimal.

\section{B.2.3. Evaluasi}

Faktor penghambat dalam evaluasi program yang ditemukan dalam penelitian ini adalah kurangnya pengetahuan pemuda mengenai tahap evaluasi dan Pembuatan dan penyampaian laporan belum dilaksanakan. Dalam penelitan Tanjung et al. (2017) menemukan keterlibatan anggota dalam diskusi monitoring evaluasi berlangsung hanya sesama pengurus dan fasilitator dan pada umumnya tidak melibatkan anggota, meskipun ada anggota yang terlibat hanya terdiri atas anggota yang dinilai aktif dan berpengaruh diantara anggota lainnya kerena memiliki posisi sosial dimasyarakat seperti Ketua 
Pemuda. Hal ini tentunya belum sejalan dengan Undang-undang Nomor 40 Tahun 2009 Pasal 20 (e) Tentang Kepemudaan bahwa setiap pemuda berhak mendapatkan kesempatan berperan serta dalam perencanaan, pelaksanaan, pengawasan, evaluasi dan pengambilan keputusan strategis program kepemudaan.

\section{Strategi Peningkatan Partisipasi Pemuda Dalam Pengelolaan Hutan Kemasyarakatan (Hkm)}

Setelah melakukan telaah terhadap permasalahan yang terjadi pada pengelolaan HKm khususnya pada partisipasi pemuda, maka penyusunan strategi didasarkan pada faktor pendorong (driving force) dan faktor penghambat (restraining force) partisipasi pemuda dalam pengelolaan $\mathrm{HKm}$. Strategi yang diperoleh dalam penelitian ini merupakan cara (ways) untuk memperkuat faktor pendorong (driving forces) dan memperlemah atau memberikan alternatif untuk mengurangi faktor penghambat (restraining forces).

Setelah strategi atau cara (ways) diperoleh, selanjutnya dirumuskan rencana aksi yang dapat dilakukan secara nyata untuk meningkatkan partisipasi pemuda dalam pengembangan Hutan Kemasyarakatan di Desa Kahayya. Adapun strategi dan rencana aksi yang telah diperoleh dari Focus Group Discussion (FGD) dan studi dokumen, disajikan dalam Tabel 6.

Tabel 6. Rencana Aksi Peningkatan Partisipasi Pemuda dalam Pengelolaan HKm di Desa Kahayya.

Table 6. Action Plan for Increasing Youth Participation in Community Forest Management in Kahayya Village.

\begin{tabular}{|c|c|c|c|}
\hline Variabel & $\begin{array}{l}\text { Cara memperkuat } \\
\text { Faktor Pendorong }\end{array}$ & $\begin{array}{l}\text { Cara memperlemah } \\
\text { Faktor Penghambat }\end{array}$ & Rencana Aksi \\
\hline Perencanaan & $\begin{array}{l}\text { Melakukan } \\
\text { pertemuan } \\
\text { membahas } \\
\text { pelaksanaan } \\
\text { penataan batas } \\
\text { areal kerja dan } \\
\text { melakukan } \\
\text { sosialisasi tentang } \\
\text { dokumen RKU dan } \\
\text { RKT }\end{array}$ & $\begin{array}{l}\text { Melakukan pertemuan } \\
\text { membahas proses } \\
\text { perencanaan } \mathrm{HKm} \\
\text { dan pembahasan } \\
\text { kegiatan penataan } \\
\text { areal kerja }\end{array}$ & $\begin{array}{l}\text { Melakukan pertemuan rutin } \\
\text { yang melibatkan } \\
\text { pendamping, kelompok tani } \\
\text { dan pemuda untuk } \\
\text { membahas pelaksanaan } \\
\text { penataan batas areal kerja } \\
\text { dan mensosialisasikan isi } \\
\text { dokumen rencana kerja HKm } \\
\text { yang telah dibuat. }\end{array}$ \\
\hline Pelaksanaan & $\begin{array}{l}\text { 1. Meningkatkan } \\
\text { pertisipasi } \\
\text { pemuda dan } \\
\text { melakukan } \\
\text { pelatihan } \\
\text { peningkatan } \\
\text { kapasitas } \\
\text { pemuda dalam } \\
\text { pengelolaan } \\
\text { HKm. } \\
\text { 2. Meningkatkan } \\
\text { peran KUPS dan } \\
\text { memaksimalkan } \\
\text { penggunaan alat } \\
\text { bantuan ekonomi } \\
\text { produktif }\end{array}$ & $\begin{array}{l}\text { Meningkatkan peran } \\
\text { KTH, meningkatkan } \\
\text { pemahaman pemuda } \\
\text { dalam proses } \\
\text { pelaksanaan HKm } \\
\text { sesuai Rencana Kerja } \\
\text { yang telah disusun. } \\
\text { Membuat aturan } \\
\text { internal mengenai } \\
\text { penentuan harga, dan } \\
\text { meningkatkan peran } \\
\text { KUPS. }\end{array}$ & $\begin{array}{l}\text { 1. Melaksanakan rapat } \\
\text { internal KTH membahas } \\
\text { rencana kerja yang telah } \\
\text { disusun. } \\
\text { 2. Membuat aturan internal } \\
\text { kelompok mengenai } \\
\text { harga penjualan produk. } \\
\text { 3. Meningkatkan peran } \\
\text { KUPS dan melakukan } \\
\text { pelatihan bagi pengurus } \\
\text { KUPS untuk } \\
\text { meningkatkan } \\
\text { kapasitasnya. } \\
\text { 4. Pemuda ikut serta dalam } \\
\text { berbagai jenis pelatihan } \\
\text { yang dilakukan oleh } \\
\text { pemerintah maupun } \\
\text { lembaga non pemerintah }\end{array}$ \\
\hline
\end{tabular}


(LSM) yang dapat

meningkatkan

kapasitasnya.

Lanjutan Tabel 6. Rencana Aksi Peningkatan Partisipasi Pemuda dalam Pengelolaan HKm di Desa Kahayya.

Continued Table 6. Action Plan for Increasing Youth Participation in Community Forest Management in Kahayya Village.

\begin{tabular}{|c|c|c|c|}
\hline Variabel & $\begin{array}{l}\text { Cara memperkuat } \\
\text { Faktor Pendorong }\end{array}$ & $\begin{array}{l}\text { Cara memperlemah } \\
\text { Faktor Penghambat }\end{array}$ & Rencana Aksi \\
\hline Evaluasi & $\begin{array}{l}\text { Melakukan } \\
\text { pertemuan dengan } \\
\text { melibatkan pemuda } \\
\text { dalam proses } \\
\text { pembuatan dan } \\
\text { penyampaian } \\
\text { laporan. }\end{array}$ & $\begin{array}{l}\text { Melakukan } \\
\text { pertemuan/ sosialisasi } \\
\text { pembahasan } \\
\text { mengenai tahap } \\
\text { evaluasi program dan } \\
\text { melibatkan pemuda } \\
\text { pada saat pembuatan } \\
\text { laporan. }\end{array}$ & $\begin{array}{l}\text { Melaksanakan rapat dan/atau } \\
\text { sosialisasi mengenai tahapan } \\
\text { proses evaluasi program dan } \\
\text { melibatkan pemuda dalam } \\
\text { pembuatan dan penyampaian } \\
\text { laporan }\end{array}$ \\
\hline
\end{tabular}

Sumber: Analisis Data Primer, 2020

\section{KESIMPULAN DAN SARAN}

Tingkat partisipasi pemuda dalam pengelolaan Hutan Kemasyarakatan $(\mathrm{HKm}) \mathrm{di}$ Desa Kahayya Kecamatan Kindang Kabupaten Bulukumba, sebagian besar berada pada tingkat Non-Partisipation dengan persentase 71,43\%. Faktor pandorong (driving force) partisipasi pemuda dalam pengelolaan $\mathrm{HKm}$ terdiri atas: adanya pendamping kelompok, adanya pertemuan kelompok, adanya dokumen rencana kerja, adanya bantuan dari berbagai pihak, adanya Kelompok Usaha Perhutanan Sosial (KUPS) dan adanya keinginan pemuda berpartisipasi dalam setiap tahap pembangunan $\mathrm{HKm}$. Sedangkan faktor penghambat (restrainging force) partisipasi pemuda dalam pengelolaan HKm terdiri atas: kurangnya pengetahuan pemuda mengenai tahap-tahap pembangunan $\mathrm{HKm}$, belum terlaksananya penataan batas areal kerja, Pemuda tidak dilibatkan dalam proses pembuatan rencana kerja, pada tahap pelaksanaan $\mathrm{HKm}$ masih dilakukan secara sendirisendiri, pengalaman bertani masih kurang, modal kelompok tidak ada yang mengakibatkan harga jual bahan baku tidak stabil.

Strategi yang sesuai dalam peningkatan partisipasi pemuda dalam pengelolaan $\mathrm{HKm}$ terdiri atas: Melakukan pertemuan yang melibatkan pendamping, kelompok tani dan pemuda untuk membahas pelaksanaan kegiatan pengelolaan (perencanaan, pelaksanaan \& evaluasi) $\mathrm{HKm}$. melakukan sosialisasi dan rapat mengenai isi dokumen rencana kerja $\mathrm{HKm}$ yang telah dibuat. Membuat aturan internal kelompok mengenai harga penjualan produk. Meningkatkan peran KUPS dan melakukan pelatihan bagi pengurus KUPS untuk meningkatkan kapasitasnya. Pemuda ikut serta dalam berbagai jenis pelatihan yang dilakukan oleh pemerintah maupun lembaga non pemerintah (LSM). 


\section{DAFTAR PUSTAKA}

Arifandy, M. I., \& Sihaloho, M. (2015). Effectiveness of Community Based Forest Managementas Forest Resources Conflict Resolution. Sodality: Jurnal Sosiologi Pedesaan, 3(2).

Arnstein, S. R. (1969). A ladder of citizen participation. Journal of the American Institute of planners, 35(4), 216-224.

Dewi, I.N., Andayani, W. and Suryanto, P. (2018). Karakteristik petani dan kontribusi hutan kemasyarakatan $(\mathrm{HKm})$ terhadap pendapatan petani di Kulon Progo. Jurnal IImu Kehutanan, 12(1): 86-98.

Hikmah, N., Mahbub, A. S., and Supratman, S. (2018). Strategi Pengembangan Program Pemberdayaan Masyarakat Hutan Kemasyarakatan di Desa Gunung Silanu Kecamatan Bangkala Kabupaten Jeneponto. Jurnal Hutan Dan Masyarakat, 10(2), 246-256.

Kaskoyo, H., Mohammed, A.J. and Inoue, M. (2014). Present state of community forestry (Hutan Kemasyarakatan/HKm) program in a protection forest and its challenges: Case study in Lampung Province, Indonesia. Journal of Forest Science, 30(1).

Kementerian Lingkungan Hidup dan Kehutanan. (2016). Peraturan Menteri Lingkungan Hidup dan Kehutanan Republik Indonesia, Nomor: P.83/Menlhk/Setjen/Kum.1/10/2016. Tentang Perhutanan Sosial. Jakarta.

Lewin, K. (1946). Force field analysis. The 1973 annual handbook for group facilitators, 111-13.

Mulyadin, R. M., Surati, S., and Ariawan, K. (2016). Kajian Hutan Kemasyarakatan sebagai Sumber Pendapatan: Kasus di Kab. Gunung Kidul. Jurnal Penelitian Sosial dan Ekonomi Kehutanan, 13(1), 13-23.

Nandini, R. (2013). Evaluasi pengelolaan Hutan Kemasyarakatan (HKm) pada hutan produksi dan hutan Lindung di Pulau Lombok. Jurnal penelitian hutan tanaman, 10(1): 43-55.

Ramdhani, H. Nulhaqim, S. A., and Fedryansyah, M. (2015). Peningkatan Kesejahteraan Petani dengan Penguatan Kelompok Tani. Prosiding Penelitian dan Pengabdian kepada Masyarakat, 2(3)

Republik Indonesia. (1999). Undang-Undang Republik Indonesia Nomor 41 Tahun 1999 tentang Kehutanan. Lembaran Negara Republik Indonesia Tahun 1999 Nomor 167. Sekretariat Negara. Jakarta.

Republik Indonesia. (2009). Undang-Undang Republik Indonesia Nomor 40 Tahun 2009 tentang Kepemudaan. Lembaran Negara Republik Indonesia Tahun 2009 Nomor 148. Sekretariat Negara. Jakarta.

Reski, N.A., Yusran, Y. and Makkarennu, M. (2017). Rancangan Pemberdayaan Masyarakat pada Pengelolaan Hutan Kemasyarakatan (HKm) Desa Pacekke, Kecamatan Soppeng Riaja, Kabupaten Barru, Sulawesi Selatan. Jurnal Hutan dan Masyarakat, 9(1), 37-43.

Ruhimat, I.S. (2013). Model Peningkatan Partisipasi Masyarakat dalam Implementasi Kebijakan Kesatuan Pengelolaan Hutan: Studi Kasus di KPH Model Kabupaten Banjar, Kalimantan Selatan. Jurnal Analisis Kebijakan Kehutanan Vol.10 No.3. 255-267.

Satriani, I., Muljono, P., and Lumintang, R.W.E. (2015). Komunikasi Partisipatif Pada Program Pos Pemberdayaan Keluarga (Studi Kasus di RW 05 Kelurahan Situgede, Kecamatan Bogor Barat, Kota Bogor). Jurnal Komunikasi Pembangunan, 9(2).

Sinery, A.S. and Manusawai, J. (2016). Partisipasi Masyarakat Dalam Program Pengelolaan Hutan Lindung Wosi Rendani (Participation of Communities in the Wosi Rendani Protected Forest Management). Jurnal Manusia dan Lingkungan, 23(3), pp.394-401. 
Tanjung, N.S. Sadono, S. and Wibowo, C.T. (2017). Tingkat Partisipasi Masyarakat dalam Pengelolaan Hutan Nagari di Sumatera Barat. Jurnal Penyuluhan. Vol.13 No.1.

Winata A, and Yuliana E. (2012). Tingkat Partisipasi Petani Hutan dalam Program Pengelolaan Hutan Bersama Masyarakat (PHBM) Perhutani. Jurnal Mimbar 28 (1): $65-76$. 